\title{
Sistem Pendukung Keputusan Untuk Menentukan Kelayakan Bus Berdasarkan Uji Kir Menggunakan Metode Promethee II (Studi Kasus: Dinas Perhubungan Provinsi Sumatera Utara)
}

\author{
Supirman, Murdani \\ Program Studi Teknik Informatika, STMIK Budi Darma, Medan, Indonesia \\ Email: supirman639@gmail.com \\ Submitted 16-04-2020; Accepted 25-04-2020; Published 26-04-2020
}

\begin{abstract}
Abstrak
Salah satu syarat bus/angkutan umum untuk bisa beroperasi adalah lulus pada uji kir yang dilakukan oleh Dinas Perhubungan. Hasil dari uji kir kelayakan angkutan masih menggunakan perhitungan manual, sedangkan banyak angkutan yang melakukan uji kir setiap harinya. Oleh karena itu diperlukan sistem pendukung keputusan untuk menentukan kelayakan bus berdasarkan uji kir. Penelitian ini bertujuan untuk menentukan kelayakan bus berdasarkan uji kir. Bus yang layak akan mendapatkan surat kelayakan jalan yang dikeluarkan oleh Dinas Perhubungan. Dalam pengujian dibutuhkan manajemen perencanaan yang baik salah satunya dengan cara menentukan kelayakan tersebut. Sistem pendukung keputusan ini, dapat menentukan nilai perhitungan terhadap semua kriteria. Sistem ini menggunakan metode Promethee II. Pada kasus ini metode Promethee II dapat menentukan prioritas uji kir bus berdasarkan nilai tertinggi. Dengan demikian sistem ini mampu mempersingkat proses verifikasi bus pada Dinas Perhubungan Provinsi Sumatera Utara, sehingga membantu penguji dalam menentukan bus yang layak jalan.
\end{abstract}

Kata Kunci: Sistem Pendukung Keputusan, Kelayakan Bus, Uji Kir, Promethee II.

\section{Abstract}

One of the requirements for a bus / public transportation to be able to operate is passing the test carried out by the Transportation Department. The results of the transportation feasibility test still use manual calculations, while many transports do the daily test. Therefore a decision support system is needed to determine the feasibility of the bus based on the kir test. This study aims to determine the feasibility of the bus based on the left test. A decent bus will get a roadworthiness certificate issued by the Transportation Agency. In testing, good planning management is needed, one of which is by determining the feasibility. This decision support system can determine the calculated value of all criteria. This system uses the Promethee II method. In this case the Promethee II method can determine the priority of the bus driver test based on the highest value. Thus this system is able to shorten the bus verification process at the North Sumatra Provincial Transportation Office, thus helping testers determine which buses are worthy of road.

Keywords: Decision Support System, Bus Feasibility, Kir Test, Promethee II.

\section{PENDAHULUAN}

Sistem pendukung keputusan merupakan suatu sistem informasi berbasis komputer yang menghasilkan berbagai alternatif keputusan untuk membantu manajemen dalam menangani berbagai permasalahan di dalam suatu perusahaan atau instansi[1], [2]. Suatu perusahaan atau instansi pasti memiliki beberapa permasalahan salah satunya adalah masalah dalam pengambilan sebuah keputusan. Tidak terkecuali instansi pemerintahan khususnya Dinas Perhubungan Provinsi Sumatera Utara.

Dinas Perhubungan Provinsi Sumatera Utara mempunyai peranan penting sebagai Dinas yang menangani bidang transportasi secara umum termasuk pengujian kendaraan. Sehubungan dengan usaha-usaha untuk meningkatkan pelayanan terbaik kepada masyarakat, salah satu upaya yang dilakukan oleh pemerintah daerah kota medan adalah dengan meningkatkan pelayanan kepada masyarat dibidang angkutan kota.

Dinas Perhubungan Provinsi Sumatera Utara terdapat beberapa program pemerintah salah satunya adalah uji kir. Uji kir merupakan pengujian kendaraan bermotor yang dilakukan terhadap kendaraan dengan status angkutan sewa. Pengujian ini merupakan persyaratan teknis dan perwujudan keamanan, keselamatan, ketertiban, dan kelancaran berlalu lintas dan tercatat pada pasal $48-55$ UU No. 22/2009.

Bus merupakan sarana yang diberikan pemerintah untuk melayani masyarakat. Namun sangat disayangkan masih banyak masalah yang terjadi di bus seperti tidak ada ujung penyelesaiannya. Mulai dari lemahnya kesadaran pengemudi dan pemilik untuk mengetahui apakah kendaraan memenuhi spesifikasi teknis yang dibutuhkan terhadap keadaan kendaraan yang mungkin bisa mengakibatkan polusi atau bahkan kecelakaan, uji kir berguna untuk menghindari hal semacam itu.

Promethee merupakan metode yang sederhana dengan proses perhitungan dan analisis yang jelas sehingga diharapkan promethee dapat memberikan solusi untuk permasalahan dalam menentukan kelayakan bus. Promethee melakukan perankingan dengan mempertimbangkan nilai leaving flow merupakan nilai tertinggi dibanding dengan nilai data lainnya dan entering flow merupakan nilai terendah lalu akan terjadi perankingan data-data alternatif[3]. Promethee II merupakan pengembangan dari metode Promethee dengan mempertimbangkan nilai netflow dalam proses perankingan. Menurut Muhammad Wafi, Rizal Setya Perdana, Wijaya Kurniawan, jurnal berjudul Implementasi Metode Promethee II Untuk Menentukan Pemenang Tender Proyek. Pada penelitian tersebut dapat diambil beberapa kesimpulan diantaranya metode Promethee II menggunakan tipe preferensi yang berbeda dalam perhitungan pemilihan pemenang tender antara lain fungsi preferensi dan preferensi agregat, dan memiliki tingkat akurasi tertinggi pada penggunaan fungsi preferensi [4]. 


\section{METODE PENELITIAN}

\subsection{Sistem Pendukung Keputusan}

Sistem pendukung keputusan adalah proses penelusuran yang berawal dari latar belakang masalah, identifikasi masalah hingga kepada terbentuknya kesimpulan atau rekomendasi. Rekomendasi itulah yang selanjutnya dipakai dan digunakan sebagai pedoman basis dalam pengambilan keputusan. Oleh karena itu, begitu besarnya pengaruh yang akan terjadi jika seandainya rekomendasi yang dihasilkan tersebut terdapat kekeliruan atau adannya kesalahan-kesalahan yang tersembunyi karena faktor ketidak hati-hatian dalam melakukan pengkajian masalah[5]-[8].

\subsection{Uji KIR}

Uji kir merupakan pengujian kendaraan yang dilakukan terhadap kendaraan dengan status angkutan sewa. Pengujian ini merupakan persyaratan teknis dan perwujudan keamanan, keselamatan, ketertiban, dan kelancaran berlalu lintas dan tercatat pada pasal $48-55$ UU No. 22/2009[9].

\subsection{PROMETHEE II}

Promethee merupakan salah satu dari metode Multi Criteria Decision Making (MCDM) yang berarti melakukan penentuan atau pengurutan dalam suatu analisis multikriteria, metode ini dikenal karena konsepnya yang efisien dan simple, selain itu untuk menyelesaikan masalah yang berhubungan dengan multikriteria, metode ini juga sangat mudah untuk diterapkan dari pada metode lainnya[4].

Adapun langkah-langkah prosedural dalam metode Promethee II [10]-[12], sebagai berikut :

1. Menormalisasi matriks keputusan dengan menggunakan persamaan sebagai berikut:

$$
R_{i j}=\left[X_{i j}-\min \left(X_{i j}\right)\right] /\left[\max \left(X_{i j}-\operatorname{in}\left(X_{i j}\right)\right)\right]
$$

Dimana $X \mathrm{ij}$ adalah ukuran kinerja alternatifnya sesuai kriteria $\mathrm{j}$ yang sudah ada. Untuk kriteria yang tidak menguntungkan, Eqn (1) dapat ditulis ulang sebagai berikut:

$$
R_{i j}=\left[\max \left(X_{i j}\right)-\left(X_{i j}\right)\right] /\left[\max \left(X_{i j} \min \left(X_{i j}\right)\right]\right.
$$

2. Hitung fungsi preferensi, $\mathrm{Pj}\left(\mathrm{i}, \mathrm{i}^{\prime}\right)$

Terutama ada enam jenis fungsi preferensi umum seperti yang diusulkan oleh Brans dan Mareschal. Namun, fungsi preferensi ini memerlukan definisi beberapa parameter preferensial, seperti preferensi dan batasan ketidakpedulian. Namun, dalam aplikasi real time, mungkin sulit bagi pengambil keputusan untuk menentukan fungsi preferensi spesifik yang sesuai untuk setiap kriteria dan juga untuk menentukan parameter yang terlibat. Untuk menghindari masalah ini, fungsi preferensi disederhanakan berikut diadopsi di sini:

$$
\begin{aligned}
& P_{j}\left(\mathrm{i}, \mathrm{i}^{\prime}\right)=0 \text { jika } R_{i j} \leq R_{i^{\prime} j} \\
& P_{j}\left(\mathrm{i}, \mathrm{i}^{\prime}\right)=\left(R_{i j^{\prime}}-R_{i^{\prime} j}\right) \text { jika } R_{i j}>R_{i^{\prime} j}
\end{aligned}
$$

3. Hitung fungsi preferensi agregat dengan mempertimbangkan bobot kriteria.

Fungsi preferensi agregat :

$$
\pi\left(\mathrm{i}, \mathrm{i}^{\prime}\right)=\left[\sum_{j=1}^{m} W_{j} \cdot P_{j}\left(i, i^{\prime}\right)\right] / \sum_{j=1}^{m} W_{j}
$$

Dimana wj adalah kriteria kepentingan relatif (berat) dari jth.

4. Tentukan arus keluar dan arus outranking sebagai berikut:

Aliran (atau positif) untuk alternatif:

$$
\varphi(\mathrm{i})=\frac{1}{n-1}\left[\sum_{j^{\prime}-1}^{n} \pi\left(i, i^{\prime}\right] /(\mathrm{i} \neq \mathrm{i})\right.
$$

Memasuki arus (atau negatif) untuk alternatif:

$$
\varphi(\mathrm{i})=\frac{1}{n-1}\left[\sum_{j^{\prime}-1}^{n} \pi\left(i, i^{\prime}\right] /(\mathrm{i}=\mathrm{i})\right.
$$

Dimana $\mathrm{n}$ adalah jumlah alternatif. Di sini, setiap alternatif menghadapi $(\mathrm{n}-1)$ sejumlah alternatif lainnya. Aliran meninggalkan mengungkapkan seberapa banyak alternatif yang mendominasi alternatif lainnya, sedangkan arus masuk menunjukkan seberapa banyak alternatif didominasi oleh alternatif lainnya. Berdasarkan arus outranking ini, Promethee II dapat memberikan preorder lengkap dengan menggunakan aliran bersih, meskipun kehilangan banyak informasi tentang hubungan preferensi.

5. Hitung arus outranking bersih untuk setiap alternatif.

$$
\varphi(\mathrm{i})=\varphi^{+}(i)-\varphi^{-}(\mathrm{i})
$$

6. Menentukan rangking semua alternatif yang dipertimbangkan tergantung pada nilai $\varphi$ (i). Nilai yang lebih tinggi dari $\Phi$ (i), semakin bagus alternatifnya. Dengan demikian, alternatif terbaik adalah yang memiliki nilai $\varphi$ (i) tertinggi. Metode Promethee adalah pendekatan pengambilan keputusan multi kriteria yang interaktif yang dirancang untuk menangani kriteria kuantitatif maupun kualitatif dengan alternatif diskrit. Dalam metode ini, perbandingan dua alternatif dilakukan untuk menghitung fungsi preferensi untuk setiap kriteria. Berdasarkan fungsi preferensi ini, indeks preferensi. Untuk alternatif i over i ditentukan. Indeks preferensi ini adalah ukuran untuk mendukung hipotesis bahwa alternatif i lebih disukai dari pada i. 


\section{HASIL DAN PEMBAHASAN}

Masalah yang sering dihadapi pada saat menentukan kelayakan bus pada Dinas Perhubungan Provinsi Sumatera Utara adalah bahwa tim penguji kir hanya berpatokan kepada hal tertentu sebagai bahan acuan dalam menentukan kelayakan bus. Proses menentukan kelayakan bus berdasarkan uji kir dengan cara pengujian kendaraan sesuai dengan prosedur kir. Setiap Kendaraan yang telah selesai dan lulus akan mendapatkan buku uji, plat uji, stiker tanda samping dan mendapatkan surat layak jalan. Sementara itu kendaraan yang gagal dalam uji kir dapat langsung diperbaiki oleh bengkel yang disediakan sehingga dapat langsung menjalani uji kir ulang.

Untuk mempermudah dalam menentukan kelayakan bus berdasarkan uji kir metode yang diterapkan yaitu Promethee II. Untuk dapat menerapkan metode maka harus terlebih dahulu menentukan kriteria uji, bobot dan alternatif uji dan membuat matriks dari nilai alternatif, untuk nilai normalisasi maka dilakukan pembagian pada matriks awal. Setelah didapatkan nilai normalisasi maka selanjutnya menentukan fungsi preferensi, selanjutnya menentukan nilai preferensi agregat. Kemudian menentukan arus dan outranking setelah didapat nilai outranking selanjutnya menentukan rangking.

Dalam menentukan kelayakan bus dengan menggunakan metode Promethee II diperlukan kriteria-kriteria dan bobot untuk melakukan perhitungannya sehingga akan didapat alternatif terbaik, dalam hal ini alternatif yang dimaksud adalah yang berhak mendapatkan layak jalan berdasarkan kriteria-kriteria yang ditentukan.

1. Kriteria Dan Bobot

Kriteria yang menjadi bahan pertimbangan adalah sebagai berikut :

Tabe 1. Tabel Kriteria

\begin{tabular}{cc}
\hline Kriteria & Keterangan \\
\hline C1 & Mesin dan Transmisi \\
C2 & Sistem Kemudi \\
C3 & Sistem Pengereman \\
C4 & Sistem Penerangan \\
C5 & Rangka dan Body Bus \\
C6 & Ban dan Velg Bus \\
\hline
\end{tabular}

Dari masing-masing kriteria tersebut akan ditentukan bobot-bobotnya. Pada bobot terdiri dari empat bilangan fuzzy, yaitu tidak lsyak (TL), cukup layak (CL), layak (L), dan sangat layak (SL) seperti dalam tabel 2.

Tabel 2. Bobot

\begin{tabular}{cc}
\hline Bilangan Fuzzy & Nilai \\
\hline Sangat Layak (SL) & 40 \\
Layak (L) & 30 \\
Cukup Layak (CL) & 20 \\
Tidak Layak (TL) & 10 \\
\hline
\end{tabular}

Pada pembobotan tiap-tiap kriteria ditentukan dari tingkat kepentingan masing-masing kriteria. Berdasarkan nilai bobot terhadap kepentingan dari masing-masing kriteria maka bobot awal untuk setiap kriteria (C1-C6) dari setiap alternatif dapat dilihat pada tabel 3. berikut ini.

Tabel 3. Data Bobot Setiap Kriterian

\begin{tabular}{lll}
\hline Mesin dan Transmisi & Bilangan Fuzzy & Nilai \\
Suara Mesin Halus & Sangat Layak (SL) & 40 \\
Masalah Pada Engine Mounting & Layak (L) & 30 \\
Kebocoran Tempat Oli & Cukup Layak (CL) & 20 \\
Plat Kopling Sudah Tipis & Tidak Layak (TL) & 10 \\
Sistem Kemudi & & \\
Kinerja Kemudi Stabil & Sangat Layak (SL) & 40 \\
Getaran Kuat Pada Kemudi & Layak (L) & 30 \\
Rusaknya Understeel & Cukup Layak (CL) & 20 \\
Gerak Kemudi Terlalu Bebas & Tidak Layak (TL) & 10 \\
Sistem Pengereman & & \\
Rem Stabil & Sangat Layak (SL) & 40 \\
Muncul Suara Berdecit & Layak (L) & 30 \\
Rem Keras Saat Diinjak & Cukup Layak (CL) & 20 \\
Rem Menjadi Lebih Dalam & Tidak Layak (TL) & 10 \\
Sistem Penerangan & & \\
Semua Lampu Menyala & Sangat Layak (SL) & 40 \\
Lampu Menyala Tidak Terang & Layak (L) & 30 \\
Sebuah Lampu Tidak Menyala & Cukup Layak (CL) & 20 \\
\hline
\end{tabular}




\begin{tabular}{lll}
\hline Semua Lampu Tidak Menyala & Tidak Layak (TL) & 10 \\
Rangka dan Body Bus & & \\
Body Mulus & Sangat Layak (SL) & 40 \\
Retakan Pada Kaca Depan & Layak (L) & 30 \\
Bemper Penyok & Cukup Layak (CL) & 20 \\
Kerusakan Pada Rangka Penopang & Tidak Layak (TL) & 10 \\
Ban dan Velg Bus & & \\
Keadaan Ban dan Velg Masih Bagus & Sangat Layak (SL) & 40 \\
Casing Break Up & Layak (L) & 30 \\
Sidewall Putus & Cukup Layak (CL) & 20 \\
Motif Tapak Terangkat & Tidak Layak (TL) & 10 \\
\hline
\end{tabular}

2. Menentukan Alternatif

Untuk mempermudah perhitungan dengan metode Promethee II, setiap alternatif diberikan kode sesuai dengan kode yang sudah ditentukan. Berikut ini adalah data alternatif uji kir bus.

Tabel 4. Data alternatif

\begin{tabular}{|c|c|c|c|c|c|c|}
\hline NOPOL & $\mathrm{C} 1$ & $\mathrm{C} 2$ & C3 & $\mathrm{C} 4$ & $\mathrm{C} 5$ & C6 \\
\hline $\begin{array}{l}\text { BK } 1687 \text { IA } \\
\text { (P1) }\end{array}$ & $\begin{array}{l}\text { Suara Mesin } \\
\text { Masih Halus }\end{array}$ & $\begin{array}{c}\text { Kinerja } \\
\text { Kemudi Stabil }\end{array}$ & Rem Stabil & $\begin{array}{c}\text { Semua } \\
\text { Lampu } \\
\text { Menyala }\end{array}$ & Body Mulus & $\begin{array}{c}\text { Keadaan Ban } \\
\text { dan Velg } \\
\text { Masih Bagus }\end{array}$ \\
\hline $\begin{array}{l}\text { BK } 1730 \mathrm{LD} \\
(\mathrm{P} 2)\end{array}$ & $\begin{array}{l}\text { Masalah Pada } \\
\text { Engine } \\
\text { Mounting }\end{array}$ & $\begin{array}{l}\text { Gerak Kemudi } \\
\text { Terlalu Bebas }\end{array}$ & $\begin{array}{l}\text { Muncul } \\
\text { Suara } \\
\text { Berdecit }\end{array}$ & $\begin{array}{c}\text { Semua } \\
\text { Lampu Tidak } \\
\text { Menyala }\end{array}$ & $\begin{array}{l}\text { Retakan Pada } \\
\text { Kaca Depan }\end{array}$ & $\begin{array}{c}\text { Motif Tapak } \\
\text { Terangkat }\end{array}$ \\
\hline BK 3637 & Plat Kopling & Rusaknya & Rem & Lampu & Kerusakan Pada & Sidewall \\
\hline DO (P3) & Sudah Tipis & Understeel & $\begin{array}{l}\text { Menjadi } \\
\text { Lebih } \\
\text { Dalam }\end{array}$ & $\begin{array}{c}\text { Menyala } \\
\text { Tidak Terang }\end{array}$ & $\begin{array}{c}\text { Rangka } \\
\text { Penopang }\end{array}$ & Putus \\
\hline $\begin{array}{l}\text { BK } 7390 \\
\text { AA (P4) }\end{array}$ & $\begin{array}{l}\text { Kebocoran } \\
\text { Tempat Oli }\end{array}$ & $\begin{array}{l}\text { Getaran Kuat } \\
\text { Pada Kemudi }\end{array}$ & $\begin{array}{l}\text { Rem } \\
\text { Menjadi } \\
\text { Lebih } \\
\text { Dalam }\end{array}$ & $\begin{array}{c}\text { Sebuah } \\
\text { Lampu Tidak } \\
\text { Menyala }\end{array}$ & Bemper Penyok & $\begin{array}{c}\text { Casing Break } \\
\text { Up }\end{array}$ \\
\hline $\begin{array}{l}\text { BK } 7199 \\
\text { UA (P5) }\end{array}$ & $\begin{array}{l}\text { Masalah Pada } \\
\text { Engine } \\
\text { Mounting }\end{array}$ & $\begin{array}{l}\text { Gerak Kemudi } \\
\text { Terlalu Bebas }\end{array}$ & $\begin{array}{l}\text { Rem Keras } \\
\text { Saat Diinjak }\end{array}$ & $\begin{array}{c}\text { Semua } \\
\text { Lampu Tidak } \\
\text { Menyala }\end{array}$ & $\begin{array}{c}\text { Kerusakan Pada } \\
\text { Rangka } \\
\text { Penopang }\end{array}$ & $\begin{array}{l}\text { Sidewall } \\
\text { Putus }\end{array}$ \\
\hline $\begin{array}{c}\text { BK } 5341 \text { AB } \\
\text { (P6) }\end{array}$ & $\begin{array}{l}\text { Plat Kopling } \\
\text { Sudah Tipis }\end{array}$ & $\begin{array}{l}\text { Rusaknya } \\
\text { Understeel }\end{array}$ & $\begin{array}{l}\text { Rem } \\
\text { Menjadi } \\
\text { Lebih } \\
\text { Dalam } \\
\end{array}$ & $\begin{array}{c}\text { Sebuah } \\
\text { Lampu Tidak } \\
\text { Menyala }\end{array}$ & $\begin{array}{c}\text { Kerusakan Pada } \\
\text { Rangka } \\
\text { Penopang }\end{array}$ & $\begin{array}{c}\text { Motif Tapak } \\
\text { Terangkat }\end{array}$ \\
\hline
\end{tabular}

Sampel kasus dilakukan dengan mendapatkan data kriteria yang akan diuji. Data kriteria dibandingkan dengan data bobot. Sampel perhitungan menggunakan Promethee II dapat diterapkan pada bus yang mengalami C1, C2, C3, C4, C5, dan C6.

Tabel 5. Data Perhitungan

\begin{tabular}{ccccccc}
\hline A & C1 & C2 & C3 & C4 & C5 & C6 \\
\hline (P1) & 40 & 40 & 30 & 40 & 40 & 10 \\
$(\mathrm{P} 2)$ & 30 & 10 & 30 & 10 & 30 & 10 \\
$(\mathrm{P} 3)$ & 10 & 20 & 10 & 30 & 10 & 20 \\
$(\mathrm{P} 4)$ & 20 & 30 & 10 & 20 & 20 & 30 \\
$(\mathrm{P} 5)$ & 30 & 10 & 20 & 10 & 10 & 20 \\
(P6) & 10 & 20 & 10 & 20 & 10 & 10 \\
\hline
\end{tabular}

Langkah penyelesaian:

Nilai bobot (W) = Mesin dan Transmisi (4), Sistem Kemudi (4), Sistem Pengereman (4), Sistem Penerangan (4), Rangka dan Body Bus (4), Ban dan Velg Bus (4), Alternatif (N) = 10

Matriks awal : 


$$
C=\left\{\begin{array}{llllll}
40 & 40 & 30 & 40 & 40 & 10 \\
30 & 10 & 30 & 10 & 30 & 10 \\
10 & 20 & 10 & 30 & 10 & 20 \\
20 & 30 & 10 & 20 & 20 & 30 \\
30 & 10 & 20 & 10 & 10 & 20 \\
10 & 20 & 10 & 20 & 10 & 10
\end{array}\right\}
$$

Langkah 1 : Menormalisasi matriks keputusan dengan menggunakan persamaan berikut :

Normalisasi Matriks $\mathrm{C}$ baris pertama

$$
\begin{aligned}
C_{11} & =(40-10) /(40-10) \\
& =30 / 30 \\
& =1 \\
C_{12} & =(40-10) /(40-10) \\
& =30 / 30 \\
& =1
\end{aligned}
$$

Dan seterusnya Adapun hasil normalisasi matriks terlihat pada table dibawah ini:

Tabel 6. Hasil Normalisasi Matriks C

\begin{tabular}{lllllll}
\hline P1 & 1 & 1 & 0.667 & 1 & 1 & 0.33 \\
P2 & 0.667 & 0 & 0.667 & 0 & 0.667 & 0 \\
P3 & 0 & 0.33 & 0.33 & 0.667 & 0 & 0.33 \\
P4 & 0.33 & 0.667 & 0 & 0.33 & 0.33 & 0.667 \\
P5 & 0.667 & 0 & 0.33 & 0 & 0 & 0.33 \\
P6 & 0 & 0.33 & 0 & 0.33 & 0 & 0 \\
\hline
\end{tabular}

Langkah 2 : Hitung fungsi preferensi

$$
\text { Preferensi P1 }
$$

$$
\begin{aligned}
P_{12}= & 1 \leq 0.667=1-0.667=0.333 \\
& 1 \leq 0=1-0=1 \\
& 0.667 \leq 0.667=0 \\
& 1 \leq 0=1-0=1 \\
& 1 \leq 0.667=1-0.667=0.333 \\
& 0.33 \leq 0=0.33-0=0.33 \\
P_{13}= & 1 \leq 0=1-0=1 \\
& 1 \leq 0.33=1-0.33=0.67 \\
& 0.667 \leq 0.33=0.667-0.33=0.337 \\
& 1 \leq 0.667=1-0.667=0.333 \\
& 1 \leq 0=1-0=1 \\
& 0.33 \leq 0.33=0
\end{aligned}
$$

Dan seterusnya Adapun hasil preferensi matriks $\mathrm{C}$ terlihat pada table dibawah ini:

Tabel 7. Hasil preferensi matriks C

\begin{tabular}{lllllll}
\hline$P_{12}$ & 0.333 & 1 & 0 & 1 & 0.333 & 0.33 \\
$P_{13}$ & 1 & 0.67 & 0.337 & 0.333 & 1 & 0 \\
$P_{14}$ & 0.67 & 0.333 & 0.667 & 0.67 & 0.67 & 0 \\
$P_{15}$ & 0.333 & 1 & 0.337 & 1 & 1 & 0 \\
$P_{16}$ & 1 & 0.67 & 0.667 & 0.67 & 1 & 0.33 \\
$P_{21}$ & 0 & 0 & 0 & 0 & 0 & 0 \\
$P_{23}$ & 0.667 & 0 & 0.337 & 0 & 0.667 & 0 \\
$P_{24}$ & 0.337 & 0 & 0.667 & 0 & 0.337 & 0 \\
$P_{25}$ & 0 & 0 & 0.337 & 0 & 0.667 & 0 \\
$P_{26}$ & 0.667 & 0 & 0.667 & 0 & 0.667 & 0 \\
$P_{31}$ & 0 & 0 & 0 & 0 & 0 & 0 \\
$P_{32}$ & 0 & 0.33 & 0 & 0.667 & 0 & 0.33 \\
$P_{34}$ & 0 & 0 & 0.33 & 0.337 & 0 & 0 \\
$P_{35}$ & 0 & 0.33 & 0 & 0.667 & 0 & 0 \\
$P_{36}$ & 0 & 0 & 0.33 & 0.337 & 0 & 0.33 \\
$P_{41}$ & 0 & 0 & 0 & 0 & 0 & 0.337 \\
$P_{42}$ & 0 & 0.667 & 0 & 0.33 & 0 & 0.667 \\
$P_{43}$ & 0.33 & 0.337 & 0 & 0 & 0.33 & 0.337 \\
$P_{45}$ & 0 & 0.667 & 0 & 0.33 & 0.33 & 0.337 \\
$P_{46}$ & 0.33 & 0.667 & 0 & 0 & 0.33 & 0.667 \\
\hline
\end{tabular}




\begin{tabular}{lllllll}
\hline$P_{51}$ & 0 & 0 & 0 & 0 & 0 & 0 \\
$P_{52}$ & 0 & 0 & 0 & 0 & 0 & 0.33 \\
$P_{53}$ & 0.667 & 0 & 0 & 0 & 0 & 0 \\
$P_{54}$ & 0.337 & 0 & 0.33 & 0 & 0 & 0 \\
$P_{56}$ & 0.667 & 0 & 0.33 & 0 & 0 & 0.33 \\
$P_{61}$ & 0 & 0 & 0 & 0 & 0 & 0 \\
$P_{62}$ & 0 & 0.33 & 0 & 0.33 & 0 & 0 \\
$P_{63}$ & 0 & 0 & 0 & 0 & 0 & 0 \\
$P_{64}$ & 0 & 0 & 0 & 0 & 0 & 0 \\
$P_{65}$ & 0 & 0.33 & 0 & 0.33 & 0 & 0 \\
\hline
\end{tabular}

Langkah 3 : Fungsi preferensi agregat

\section{Preferensi agregat $\mathrm{P} 1$}

$P_{12}=(0.333 * 4) / 40=0.0333$

$(1 * 4) / 40=0.1$

$(0 * 4) / 40=0$

$(1 * 4) / 40=0.1$

$(0.333 * 4) / 40=0.0333$

$(0.33 * 4) / 40=0.033$

$P_{13}=(1 * 4) / 40=0.1$

$(0.67 * 4) / 40=0.067$

$(0.337 * 4) / 40=0.0337$

$(0.333 * 4) / 40=0.0333$

$(1 * 4) / 40=0.1$

$(0 * 4) / 40=0$

Dan seterusnya Adapun hasil dari fungsi preferensi agregat terlihat pada table dibawah ini:

Tabel 8. Hasil dari fungsi preferensi agregat

\begin{tabular}{|c|c|c|c|c|c|c|}
\hline$P_{12}$ & 0.0333 & 0.1 & 0 & 0.1 & 0.0333 & 0.033 \\
\hline$P_{13}$ & 0.1 & 0.067 & 0.0337 & 0.0333 & 0.1 & 0 \\
\hline$P_{14}$ & 0.067 & 0.0333 & 0.0667 & 0.067 & 0.067 & 0 \\
\hline$P_{15}$ & 0.0333 & 0.1 & 0.0337 & 0.1 & 0.1 & 0 \\
\hline$P_{16}$ & 0.1 & 0.067 & 0.0667 & 0.067 & 0.1 & 0.033 \\
\hline$P_{21}$ & 0 & 0 & 0 & 0 & 0 & 0 \\
\hline$P_{23}$ & 0.0667 & 0 & 0.0337 & 0 & 0.0667 & 0 \\
\hline$P_{24}$ & 0.0337 & 0 & 0.0667 & 0 & 0.0337 & 0 \\
\hline$P_{25}$ & 0 & 0 & 0.0337 & 0 & 0.0667 & 0 \\
\hline$P_{26}$ & 0.0667 & 0 & 0.0667 & 0 & 0.0667 & 0 \\
\hline$P_{31}$ & 0 & 0 & 0 & 0 & 0 & 0 \\
\hline$P_{32}$ & 0 & 0.033 & 0 & 0.0667 & 0 & 0.033 \\
\hline$P_{34}$ & 0 & 0 & 0.033 & 0.0337 & 0 & 0 \\
\hline$P_{35}$ & 0 & 0.033 & 0 & 0.0667 & 0 & 0 \\
\hline$P_{36}$ & 0 & 0 & 0.033 & 0.0337 & 0 & 0.033 \\
\hline$P_{41}$ & 0 & 0 & 0 & 0 & 0 & 0.0337 \\
\hline$P_{42}$ & 0 & 0.0667 & 0 & 0.033 & 0 & 0.0667 \\
\hline$P_{43}$ & 0.033 & 0.0337 & 0 & 0 & 0.033 & 0.0337 \\
\hline$P_{45}$ & 0 & 0.0667 & 0 & 0.033 & 0.033 & 0.0337 \\
\hline$P_{46}$ & 0.033 & 0.0667 & 0 & 0 & 0.033 & 0.0667 \\
\hline$P_{51}$ & 0 & 0 & 0 & 0 & 0 & 0 \\
\hline$P_{52}$ & 0 & 0 & 0 & 0 & 0 & 0.033 \\
\hline$P_{53}$ & 0.0667 & 0 & 0 & 0 & 0 & 0 \\
\hline$P_{54}$ & 0.0337 & 0 & 0.033 & 0 & 0 & 0 \\
\hline$P_{56}$ & 0.0667 & 0 & 0.033 & 0 & 0 & 0.033 \\
\hline$P_{61}$ & 0 & 0 & 0 & 0 & 0 & 0 \\
\hline$P_{62}$ & 0 & 0.033 & 0 & 0.033 & 0 & 0 \\
\hline$P_{63}$ & 0 & 0 & 0 & 0 & 0 & 0 \\
\hline$P_{64}$ & 0 & 0 & 0 & 0 & 0 & 0 \\
\hline$P_{65}$ & 0 & 0.033 & 0 & 0.033 & 0 & 0 \\
\hline
\end{tabular}

Tabel 9. Hasil perhitungan di atas

\begin{tabular}{llllllll}
\hline Alternatif & P1 & P2 & P3 & P4 & P5 & P6 & Total \\
\hline
\end{tabular}




\begin{tabular}{llllllll}
\hline P1 & - & 0.5966 & 0.334 & 0.301 & 0.367 & 0.4337 & 2.0323 \\
P2 & 0 & - & 0.1671 & 0.1341 & 0.1004 & 0.2001 & 0.6017 \\
P3 & 0 & 0.1327 & - & 0.0667 & 0.0997 & 0.0997 & 0.3988 \\
P4 & 0.0337 & 0.1664 & 0.1334 & - & 0.1664 & 0.1994 & 0.6993 \\
P5 & 0 & 0.033 & 0.0667 & 0.0667 & - & 0.1327 & 0.2991 \\
P6 & 0 & 0.066 & 0 & 0 & 0.066 & - & 0.132 \\
Total & 0.0337 & 0.9947 & 0.7012 & 0.5685 & 0.7995 & 1.0656 & - \\
\hline
\end{tabular}

Langkah 4 : menentukan arus dan arus outrangking.

Untuk Leafing Flow

$P 1: \frac{1}{6-1} * 2.0323=0.40646$
$P 2: \frac{1}{6-1} * 0.6017=0.12034$

Untuk Entering Flow

$P 1: \frac{1}{6-1} * 0.0337=0.00674$

$P 2: \frac{1}{6-1} * 0.9947=0.19894$

Tabel 10. Hasil dari arus keluar dan arus outrangking

\begin{tabular}{ccc}
\hline Alternatif & Leaving Flow & Entering Flow \\
\hline P1 & 0.40646 & 0.00674 \\
P2 & 0.12034 & 0.19894 \\
P3 & 0.07976 & 0.14024 \\
P4 & 0.13986 & 0.1137 \\
P5 & 0.05982 & 0.1599 \\
P6 & 0.0264 & 0.21312 \\
\hline
\end{tabular}

Langkah 5 : Menghitung outrangking atau net flow bersih setiap alternatif

Dimana perhitungannya adalah :

$\mathrm{P} 1=0.40646-0.00674=0.39972$

$\mathrm{P} 2=0.12034-0.19894=-0.0786$

$\mathrm{P} 3=0.07976-0.14024=-0.060448$

$\mathrm{P} 4=0.13986-0.1137=0.02616$

$\mathrm{P} 5=0.05982-0.1599=-0.10008$

P6 $=0.0264-0.21312=-0.18672$

Langkah 6 : Menentukan Rangking

Tabel 11. Hasil dari outrangking bersih setiap alternatif

\begin{tabular}{ccc}
\hline Alternatif & Net Flow & Rangking \\
\hline P1 & 0.39972 & 1 \\
P2 & -0.0786 & 4 \\
P3 & -0.060448 & 3 \\
P4 & 0.02616 & 2 \\
P5 & -0.10008 & 5 \\
P6 & -0.18672 & 6 \\
\hline
\end{tabular}

Dari perhitungan alternatif diatas maka dapat disimpulkan alternatif yang sangat layak yang mendapatkan surat kelayakan jalan pada uji kir bus sesuai dengan nilai interval, maka dari itu bus yang layak adalah P1 (BK 1687 IA).

\section{KESIMPULAN}

Berdasarkan hasil dari penelitian maka dapat diambil kesimpulan sebagai berikut :

1. Proses Pemilihan kelayakan bus berdasarkan uji kir pada Dinas Perhubungan Provinsi Sumatera Utara dilakukan dengan cara pengujian bus berdasarkan kriteria, kemudian dilakukan perbandingan nilai kriteria dengan bus lainnya, agar bisa diperoleh bus layak jalan.

2. Dalam menerapkan metode Promethee II dimulai dengan pemberian nilai kriteria untuk masing-masing kriteria, Alternatif, pembobotan, perhitungan indeks preferensi, perhitungan arah preferensi, dan netflow sehingga menghasilkan nilai dari masing- masing kriteria.

3. Sistem pendukung keputusan ini dirancang menggunakan Microsoft Visual Studio 2008, sehingga dengan adanya sistem ini maka memudahkan petugas dalam melakukan pemilihan kelayakan bus berdasarkan uji kir, Sistem diharapkan dapat 
membantu peningkatan kinerja program pemilihan khusus dalam pemilihan kelayakan bus berdasarkan kriteria yang digunakan.

\section{REFERENCES}

[1] Kusrini, Konsep dan Aplikasi Sistem Pendukung Keputusan. 2007.

[2] D. Nofriansyah and S. Defit, Multi Criteria Decision Making (MCDM) pada Sistem Pendukung Keputusan. 2018.

[3] F. Adelia, D. Wahyuli, T. Imanda, and A. Perdana, "Analisis Promethee II Pada Faktor Penyebab Mahasiswa Sulit Menemukan Judul Artikel Ilmiah," vol. 17, 2018.

[4] M. Wafi, R. S. Perdana, and W. Kurniawan, "Implementasi Metode Promethee II untuk Menentukan Pemenang Tender Proyek ( Studi Kasus : Dinas Perhubungan dan LLAJ Provinsi Jawa Timur ),” vol. 1, no. 11, pp. 1224-1231, 2017.

[5] T. Limbong et al., Sistem Pendukung Keputusan: Metode \& Implementasi. Medan: Yayasan Kita Menulis, 2020.

[6] S. Kusumadewi, S. Hartati, A. Harjoko, and Retantyo Wardoyo, Fuzzy Multi-Attribute Decision Making (FUZZY MADM). 2006.

[7] Efraim Turban and Jay E. Aronson, Decision Support System and Intelligent Systems. 2001.

[8] D. Nofriansyah, Konsep Data Mining Vs Sistem Pendukung Keputusan. 2015.

[9] I. H.M.Hendrawan, “Sekilas KIR-Buku KIR,” 2016. .

[10] A. V. Manikrao and C. Shankar, "Facility Location Selection using PROMETHEE II Method," Int. Conf. Ind. Eng. Oper. Manag. Dhaka, pp. 59-64, 2010.

[11] M. Mesran, I. Saputra, and M. Ariska, "Penerapan Metode Promethee Ii Pada Sistem Layanan Dan Rujukan Terpadu ( Slrt ) ( Studi Kasus : Dinas Sosial Kabupaten Deli Serdang )," KOMIK (Konferensi Nas. Teknol. Inf. dan Komputer), vol. I, pp. $276-285,2017$.

[12] M. Mesran, P. Pristiwanto, and I. Sinaga, "Implementasi promethee ii dalam pemilihan pestisidaterbaik untukperawatandaun padatanamancabe," CESS (Journal Comput. Eng. Syst. Sci., vol. 3, no. 2, pp. 46-53, 2018. 